\title{
Artificial symbiosis for acetone-butanol-ethanol (ABE) fermentation from alkali extracted deshelled corn cobs by co-culture of Clostridium beijerinckii and Clostridium cellulovorans
}

Zhiqiang Wen ${ }^{1}$, Mianbin Wu${ }^{1}$, Yijun Lin ${ }^{1,2}$, Lirong Yang ${ }^{1}$, Jianping Lin ${ }^{1 *}$ and Peilin Cen ${ }^{1}$

\begin{abstract}
Background: Butanol is an industrial commodity and also considered to be a more promising gasoline substitute compared to ethanol. Renewed attention has been paid to solvents (acetone, butanol and ethanol) production from the renewable and inexpensive substrates, for example, lignocellulose, on account of the depletion of oil resources, increasing gasoline prices and deteriorating environment. Limited to current tools for genetic manipulation, it is difficult to develop a genetically engineered microorganism with combined ability of lignocellulose utilization and solvents production. Mixed culture of cellulolytic microorganisms and solventogenic bacteria provides a more convenient and feasible approach for ABE fermentation due to the potential for synergistic utilization of the metabolic pathways of two organisms. But few bacteria pairs succeeded in producing biobutanol of high titer or high productivity without adding butyrate. The aim of this work was to use Clostridium cellulovorans 743B to saccharify lignocellulose and produce butyric acid, instead of adding cellulase and butyric acid to the medium, so that the soluble sugars and butyric acid generated can be subsequently utilized by Clostridium beijerinckii NCIMB 8052 to produce butanol in one pot reaction.

Results: A stable artificial symbiotic system was constructed by co-culturing a celluloytic, anaerobic, butyrate-producing mesophile (C. cellulovorans 743B) and a non-celluloytic, solventogenic bacterium (C. beijerinckii NCIMB 8052) to produce solvents by consolidated bioprocessing (CBP) with alkali extracted deshelled corn cobs (AECC), a low-cost renewable feedstock, as the sole carbon source. Under optimized conditions, the co-culture degraded $68.6 \mathrm{~g} / \mathrm{L}$ AECC and produced $11.8 \mathrm{~g} / \mathrm{L}$ solvents ( $2.64 \mathrm{~g} / \mathrm{L}$ acetone, $8.30 \mathrm{~g} / \mathrm{L}$ butanol and $0.87 \mathrm{~g} / \mathrm{L}$ ethanol) in less than $80 \mathrm{~h}$. Besides, a real-time PCR assay based on the 16S rRNA gene sequence was performed to study the dynamics of the abundance of each strain during the co-culturing process, which figured out the roles of each strain at different periods in the symbiosis.

Conclusion: Our work illustrated the great potential of artificial symbiosis in biofuel production from lignocellulosic biomass by CBP. The dynamics of the abundance of $C$. beijerinckil and C. cellulovorans revealed mechanisms of cooperation and competition between the two strains during the co-culture process.
\end{abstract}

Keywords: ABE fermentation, Consolidated bioprocessing, Co-culture, Dynamics, Lignocellulose, Optimization

\footnotetext{
*Correspondence: linjp@zju.edu.cn

'Key Laboratory of Biomass Chemical Engineering of Ministry of Education, Department of Chemical and Biological Engineering, Zhejiang University, Hangzhou 310027, China

Full list of author information is available at the end of the article
} 


\section{Background}

As the main product of acetone-butanol-ethanol (ABE) fermentation, butanol is considered to be a promising gasoline substitute on account of its superior characteristics over ethanol; for example, butanol is less hygroscopic, less volatile, and has an energy density closer to that of gasoline [1]. Renewed attention has been paid to butanol production on account of the depletion of oil resources and increasing gasoline prices.

Traditional ABE fermentation methods employ corn, cassava or molasses as the substrate. However, with the rising price of these substrate materials, the feedstock cost has become a major factor determining the total economics of the ABE fermentation industry [2]. Therefore, alternative low-price renewable feedstock, including energy crops, agricultural residues, forestry and food processing wastes have been assessed for the production of $\mathrm{ABE}$. Recently, various biomass hydrolysates have been used as substrates in batch $\mathrm{ABE}$ fermentations by numerous Clostridium strains [3-8]. Unfortunately, the cost of cellulase used to hydrolyze the cellulose fraction of biomass has made these attempts economically uncompetitive, in respect that solventogenic clostridia are not able to utilize lignocellulose as a raw material directly [9].

Consolidated bioprocessing (CBP) has been suggested as an efficient and economical method for biofuels production from low-price renewable feedstock, which combines cellulase production, cellulose hydrolysis and fermentation in one reactor and offers the potential for lower costs and higher efficiency than processes featuring dedicated cellulase production [10]. To realize the potential, a single microorganism or microbial system must be developed to utilize lignocellulose at a high rate of conversion and produce solvents at high yields and titers.

Cellulase (or cellulosome) genes have been cloned into C. beijerinckii and C. acetobutylicum to produce butanol from cellulose in one pot reaction, but the level of heterologous cellulase (or cellulosome) expression was rather low [11-14]. Efforts to implant the (iso)butanol biosynthetic pathway in cellulolytic clostridia did not come up to desired objective either, and only small quantities of (iso)butanol was produced $[15,16]$. It was very difficult to produce butanol efficiently from lignocellulose directly by pure culture.

Mixed culture of cellulolytic microorganisms and solventogenic bacteria is a more convenient and feasible approach to ABE fermentation by CBP. In the community, microorganisms may develop the potential for synergistic utilization of the metabolic pathways from interspecies. Attempts at artificial symbiosis have been carried out by co-culturing solventogenic $C$. acetobutylicum and cellulolytic Clostridium cellulolyticum or Clostridium thermocellum $[17,18]$. Nevertheless, the results were far from satisfactory, requiring the addition of butyric acid to induce the solventogenic phase of $C$. acetobutylicum. In view of the phenomenon, to avoid the addition of butyric acid, C. saccharoperbutylacetonicum strain N1-4, whose induction mechanism of butanol production somewhat differs from that of other butanol-producing clostridia, was chosen as the partner for C. thermocellum [19]. This bacteria pair succeeded in manufacturing $7.9 \mathrm{~g} / \mathrm{L}$ of butanol from $40 \mathrm{~g} / \mathrm{L}$ of avicel cellulose in 11 days without adding butyrate. However,since the culture temperature of $C$. thermocellum $\left(60^{\circ} \mathrm{C}\right)$ doesn't match that of C. saccharoperbutylacetonicum $\left(37^{\circ} \mathrm{C}\right)$, the CBP has to be carried out in two stages, that is, thermophilic and subsequent mesophilic stage, exhibiting a low $\mathrm{ABE}$ productivity of $0.0375 \mathrm{~g} / \mathrm{L} / \mathrm{h}$. Further more, the crude lignocellulosic biomass (e.g. AECC) usually composed of cellulose, hemicellulose and lignin, which made CBP based on lignocellulose more complicated than that using pure cellulose. It was of high necessity to develop a novel CBP for real lignocellulosic biomass utilization.

The aim of this work was to construct a stable artificial symbiosis for efficient biobutanol production by CBP using AECC, an abundant agricultural residue after a simple pretreatment, as a low-cost feedstock. In the symbiosis, Clostridium cellulovorans 743B, an anaerobic, celluloytic and butyrate-producing mesophile [20], was selected to saccharify lignocellulose and produce butyric acid, instead of adding cellulase and butyric acid to the medium, so that the soluble sugars and butyric acid generated can be utilized by solventogenic bacteria to produce butanol. Meanwhile, C. beijerinckii NCIMB8052, one of the most conventional solventogenic clostridia, was introduced as the production strain for ABE fermentation. As C. beijerinckii can co-ferment hexose and pentose sugars [21], studies on lignocellulosic biomass-based $\mathrm{ABE}$ production by $C$. beijerinckii have intensified in the last few years $[4-7,22]$, but no study on $\mathrm{ABE}$ production with AECC involving the co-culture of two strains above has been reported. The present work involved the construction of symbiotic system for $\mathrm{ABE}$ fermentation using AECC as the raw material by co-culture of $C$. beijerinckii and C. cellulovorans, and the dynamics of the abundance of each strain during the co-culture process.

\section{Results and discussion}

Construction of symbiosis by co-culture of $C$. beijerinckii and $C$. cellulovorans with AECC as the sole carbon source

The single culture of $C$. beijerinckii displayed very poor growth on AECC. At an initial concentration of $70 \mathrm{~g} / \mathrm{L}$, less than $10 \%$ of the substrate was utilized even after 7 days of incubation, and the ABE output was rather low $(0.34 \mathrm{~g} / \mathrm{L}$ of ethanol, butanol and acetone not detected). These agreed with the observations of López-Contreras et al. [11] and indicated that C. beijerinckii is unable to produce $\mathrm{ABE}$ from $\mathrm{AECC}$ directly. 
As a celluloytic microorganism, C. cellulovorans grows well on lignocelluloses as it can produce cellulosome, a cellulose-degrading multi-enzyme complex, which can decompose cellulose more efficiently than free cellulase by adhering to the substrate and providing multi-cellulase synergy [23]. In the single culture of C. cellulovorans, $67.2 \mathrm{~g} / \mathrm{L}$ AECC was added as the sole carbon source and the $\mathrm{pH}$ was kept at 7.0 throughout. C. cellulovorans produced $6.72 \mathrm{~g} / \mathrm{L}$ of butyric acid, $3.17 \mathrm{~g} / \mathrm{L}$ of acetic acid and $0.29 \mathrm{~g} / \mathrm{L}$ of ethanol and degraded $59.7 \%$ of the substrate in $100 \mathrm{~h}$ (Figure 1A and B), about 75\% faster than AECC degraded by $C$. thermocellum strains SS21 and SS22 [24]. It was worth noting that the total sugars accumulated from the beginning of fermentation and finally achieved $11.7 \mathrm{~g} / \mathrm{L}$, including glucose, cellobiose, xylose, xylobiose, arabinose and some other kinds of fermentable sugars (Figure $1 \mathrm{C}$ ). The accumulation of fermentable sugars showed that the rate of AECC saccharification exceeded that of glycolysis. In fact, cellulolytic clostridia such as C. cellulovorans, C. cellulolyticum and $C$. thermocellum can only use small quantities of carbohydrates due to early inhibition of metabolism and growth [25]. Moreover, some papers have reported that butyric acid and acetic acid accumulated in the broth are very useful in ABE fermentation, and can be transformed into solvents during solventogenesis of C. beijerinckii [26,27]. Efficient degradation of AECC as well as sufficient accumulation of fermentable sugars and organic acids made C. cellulovorans a superior candidate for co-culture with $C$. beijerinckii.

Taking the results above into account, we established a co-culture method to produce ABE from AECC directly. C. beijerinckii and C. cellulovorans were inoculated simultaneously with an inoculum of $0.5 \%(\mathrm{v} / \mathrm{v})$ and $10 \%(\mathrm{v} / \mathrm{v})$, respectively, by volume from an exponentially growing culture. During the first $36 \mathrm{~h}$, the $\mathrm{pH}$ was kept at 7.0, the optimal $\mathrm{pH}$ for growth of $C$. cellulovorans. Figure 2 describes the time course of co-culture. The co-culture exhibited typical two-phase fermentation with acidogenesis followed by solventogenesis. Acetic and butyric acid accumulated during the initial $48 \mathrm{~h}$, and then butanol began to be produced. During solventogenesis, the $\mathrm{pH}$ slowly rebounded from 5.83 to 6.54 with the reassimilation of butyrate and acetate, which were speculated to be used as co-substrates with fermentable sugars to produce solvents [27].

In $100 \mathrm{~h}, 5.68 \mathrm{~g} / \mathrm{L}$ of $\mathrm{ABE}$ (acetone 1.11, butanol 4.11 and ethanol $0.46 \mathrm{~g} / \mathrm{L}$ ), about 10 times higher than from the single culture with $C$. beijerinckii, was produced from $46.8 \mathrm{~g} / \mathrm{L}$ of AECC (Figure 2A and B) without adding butyrate. Compared with the single culture of $C$. cellulovorans, the accumulation of total sugars decreased by $51.9 \%$, but AECC degradation increased by $16.7 \%$, which implied that the fermentable sugars were utilized by $C$. beijerinckii and the degradation of the substrate by $C$. cellulovorans was promoted
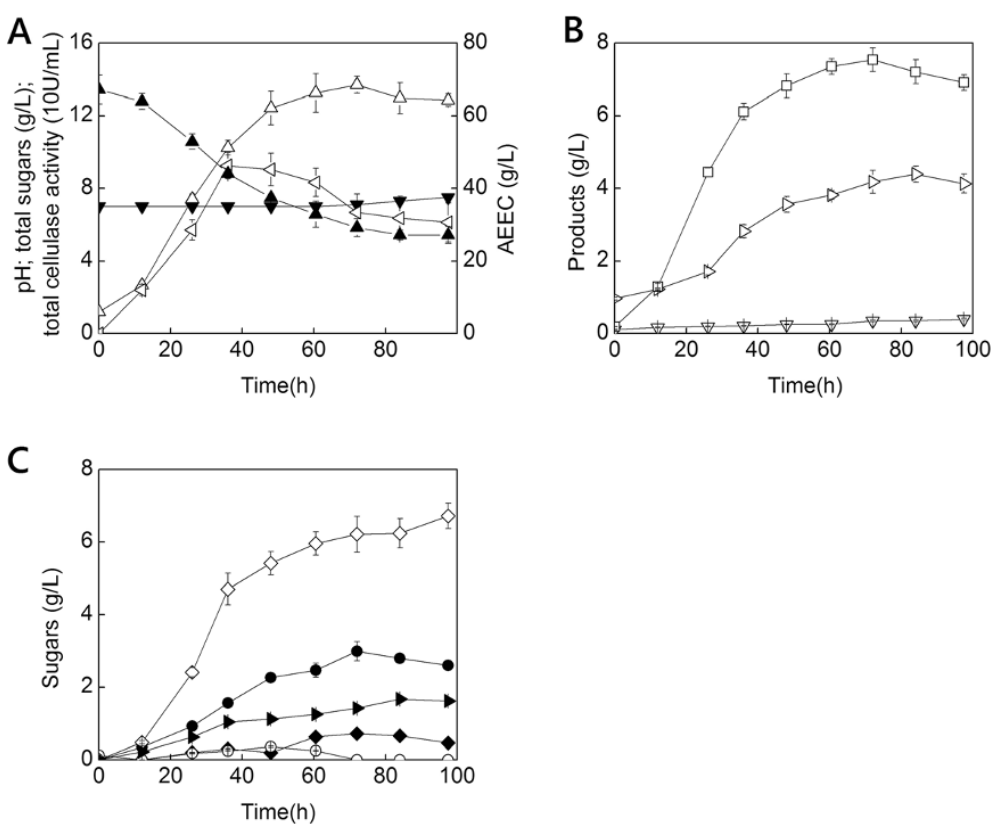

Figure 1 Time courses of single culture of $C$. cellulovorans with AECC as sole carbon source. AECC was decomposed and converted to soluble sugars and organic acids, which could be used to produced solvents in ABE fermentation. (A) Time courses of pH, total cellulase activity, total sugars accumulation and AECC degradation, (B) Time courses of organic acids and solvents production, (C) Time courses of

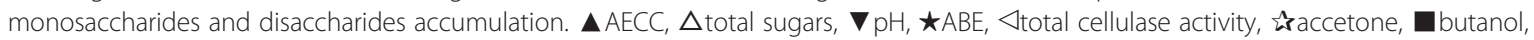
$\nabla$ ethanol, $\triangleright$ acetic acid, $\square$ butyric acid, Ocellobiose, Oglucose, $\diamond x y l o b i o s e, \diamond x y l o s e$, arabinose. 

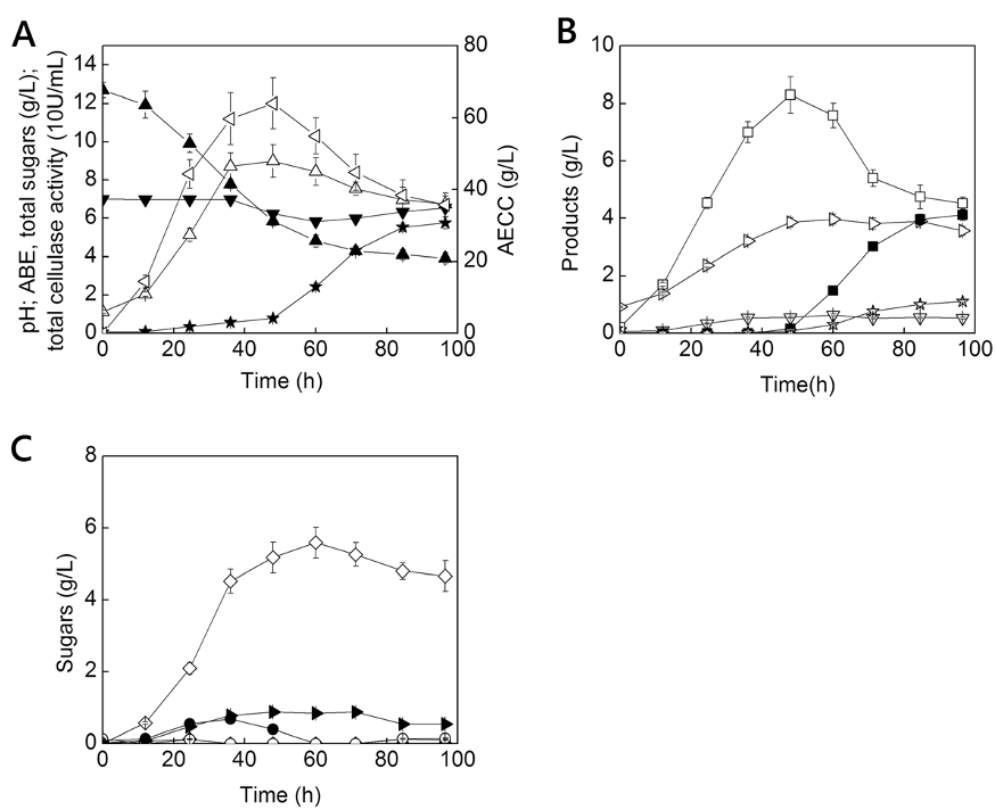

Figure 2 Time courses of co-culture of $C$. cellulovorans and C. beijerinckii with AECC as sole carbon source. The artificial symbiosis succeeded in ABE production from AECC by CBP. (A) Time courses of $\mathrm{pH}$, total cellulase activity, total sugars accumulation and AECC degradation, (B) Time organic acids and solvents production, (C) Time courses of monosaccharides and disaccharides accumulation. $\Delta$ AECC, $\triangle$ total sugars, $\mathbf{\nabla p H ,} \star A B E$,

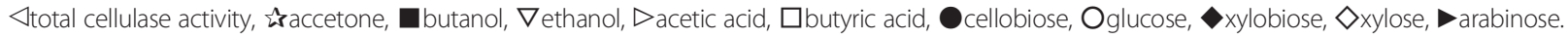

with the removal of total sugars. That was confirmed by the changes of mixed sugars components in Figures $1 \mathrm{C}$ and $2 \mathrm{C}$. In Figure $2 \mathrm{C}$, the preferred carbon sources like glucose and cellobiose almost depleted, whereas xylose and arabinose accounted for most of the residual sugars, which could be attributed to the carbon catabolite repression (CCR) mechanism [28] and inefficient pentose utilization of C. beijerinckii [29]. Besides, enhancement in the total cellulase activity also contributed to the improved AECC decomposition (Figures 1A and 2A).

In the symbiotic system, C. cellulovorans provided fermentable sugars and organic acids for $C$. beijerinckii to produce solvents. At the same time, the consumption of various sugars by $C$. beijerinckii alleviated the feedback inhibition of cellulase and improved the degradation of AECC [30]. The cooperation between the two strains was enhanced by the two-stage $\mathrm{pH}$ control strategy and butyrate accumulation in the broth. The neutral $\mathrm{pH}$ during the first $36 \mathrm{~h}$ guaranteed vigorous growth of C. cellulovorans to degrade AECC efficiently and produced sufficient organic acids, especially butyrate. With a pH decline from 7 to 5.83 since $36 \mathrm{~h}$, the butyrate "feeding" to C. beijerinckii induced solventogenesis, which thereby prevented acidogenic fermentation caused by neutral $\mathrm{pH}$ performing throughout [31].

Although ABE fermentation from AECC without addition of butyric acid was accomplished by co-culture of C. beijerinckii and C. cellulovorans, only very small quantities of solvents were produced. It was subsequently improved by optimizing some important parameters during co-culture.

\section{Optimization of the co-culture conditions}

As described above, in the symbiotic system, $C$. beijerinckii and C. cellulovorans collaborated in AECC decomposition and $\mathrm{ABE}$ production. However, they also competed for carbon sources and other nutrients to grow and metabolize. Accordingly, it was critical to ease competition and enhance cooperation by regulating some important culture conditions during the fermentation process.

Many important parameters such as inoculation timing, inoculation ratio, and the initial concentration of yeast extract and the substrate have been discussed for co-cultures $[19,32,33]$. However, few studies have focused on the effects of $\mathrm{pH}$ control in co-cultures. In the following studies, the effects of inoculation timing, inoculation ratio and the duration of $\mathrm{pH}$ control on co-cultures were investigated to improve $\mathrm{ABE}$ production and AECC degradation.

\section{Effects of $C$. beijerinckii inoculation timing on co-culture}

Because $C$. beijerinckii was unable to efficiently produce solvents from AECC directly, it was necessary to hydrolyze AECC by a single culture of $C$. cellulovorans before inoculation of $C$. beijerinckii into the co-culture. In this study, C. beijerinckii was added to the medium after inoculation and cultivated with C. cellulovorans for $0,12,24,36$ and $48 \mathrm{~h}(\mathrm{pH}$ controlled at 7.0 during the first $36 \mathrm{~h}$, inoculation ratio of $0.5: 10(\mathrm{v} / \mathrm{v})$ between $C$. beijerinckii 
and C. cellulovorans), after which butyric acid accumulation, butanol production and AECC degradation were measured at $100 \mathrm{~h}$.

Figure 3A show that delayed inoculation of $C$. beijerinckii from 0 to $48 \mathrm{~h}$ decreased butanol production from 4.07 to $1.10 \mathrm{~g} / \mathrm{L}$, and AECC decomposition from 39.7 to $32.8 \mathrm{~g} / \mathrm{L}$, respectively. In other words, the simultaneous addition of $C$. cellulovorans and $C$. beijerinckii offered the best results, which was distinguished from cocultures of C. thermocellum and C. acetobutylicum [18] or C. saccharoperbutylacetonicum strain N1-4 [19]. Since the optimal incubation temperature of C. cellulovorans matched that of solventogenic bacterium, cellulase production by $C$. cellulovorans and $\mathrm{ABE}$ fermentation by $C$. beijerinckii could be carried out simultaneously. Moreover, the inoculation of two strains in series may make $C$. beijerinckii disadvantaged in competition with C. cellulovorans, which negatively affected the utilization of fermentable sugars and the transformation of organic acids into solvents (Figure $3 \mathrm{~A}$ ).

Effects of the inoculation ratio between C. beijerinckii and C. cellulovorans on co-culture

AECC decomposition and $\mathrm{ABE}$ production depended mainly on the population and relative abundance of two strains. It has been reported that the relative abundance of $C$. thermocellum and C. thermopalmarium monitored by real-time quantitative PCR varied at different periods of coculture [32], but it was principally determined by the initial inoculation ratios. Therefore, the effects of the inoculation ratio between C. beijerinckii and C. cellulovorans on $\mathrm{ABE}$ fermentation were assessed.

To ensure the repeatability and accuracy of experiments, cell density of $C$. beijerinckii $\left(\mathrm{OD}_{600} 1.2-1.5\right)$ was previously normalized to 1.0 of $\mathrm{OD}_{600}$ before inoculating with gradient volumes. For C. cellulovorans pre-cultured for $24 \mathrm{~h}$ in $200 \mathrm{ml}$ serum bottle with AECC as sole carbon source, the cell protein content was measured and calculated as $20.7 \mathrm{mg} / \mathrm{L}$ on average. That is, cell density of C. cellulovorans used to inoculation was $36.3 \mathrm{mg} / \mathrm{L}$. In order to facilitate understanding, inoculum ratio was expressed on a volumetric basis.

Butanol production, total sugars accumulation and AECC degradation were compared among co-cultures with $C$. beijerinckii /C. cellulovorans inoculation ratios of 0:10 (single culture of C. cellulovorans), 0.25:10, 0.5:10, $1: 10$ and $2: 10(\mathrm{v} / \mathrm{v})$ for $100 \mathrm{~h}$, at $\mathrm{pH} 7.0$ during the first $36 \mathrm{~h}$ (Figure 3B). Butanol production and AECC degradation increased greatly from 0 to $5.08 \mathrm{~g} / \mathrm{L}$ and 34.7 to $49.9 \mathrm{~g} / \mathrm{L}$, respectively, with an increased abundance of $C$. beijerinckii in the inoculums. Solvents production was not apparently promoted when the ratio exceeded $1: 10$, thus, an economical inoculation ratio of $1: 10$ was adopted in our subsequent studies.

\section{Effects of $\mathrm{pH}$ control duration on co-culture}

C. cellulovorans is very sensitive to $\mathrm{pH}$, with an optimal $\mathrm{pH}$ for growth at about 7.0, and a range of 6.4 to 7.8 [20].
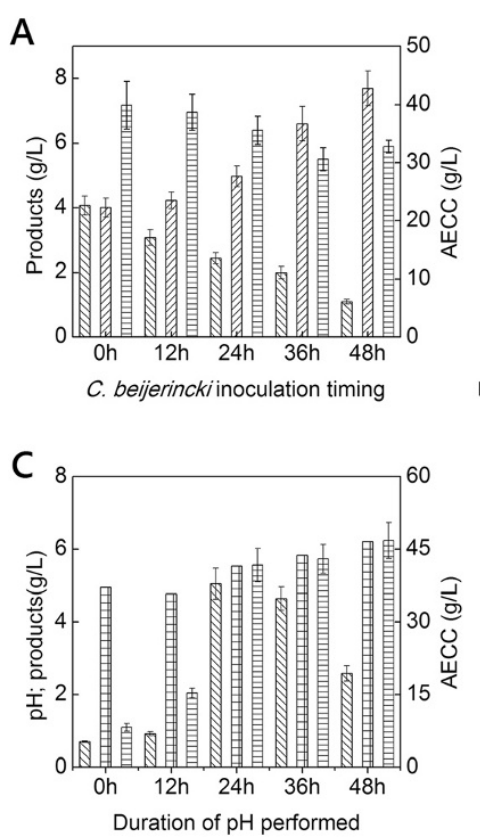

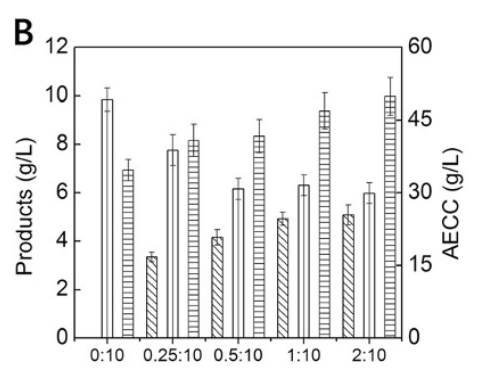

Inoculation ratio between C. beijerinckii and C. cellulovorans

Figure 3 Effects of $C$. beijerinckii inoculation timing (A), inoculation ratio (B) and pH control strategy on co-culture (C). The co-culture conditions were investigated and optimized as follows: simultaneous inoculation, inoculation ratio of 1:10(v/v) between C. beijerinckii and C. cellulovorans, pH control at 7.0 during the first 24 hours. $\mathbb{M}$. 
However, low $\mathrm{pH}$ is a prerequisite for solvents production in $\mathrm{ABE}$ fermentation, because when $\mathrm{ABE}$ fermentation is performed at a $\mathrm{pH}$ close to neutrality throughout, acids are the predominant products [31]. Therefore, during coculture, a two-stage $\mathrm{pH}$ control strategy was employed, in which the $\mathrm{pH}$ in the first stage was regulated at 7.0 to ensure vigorous growth of $C$. cellulovorans, so that cellulosomes could be produced sufficiently to hydrolyze AECC efficiently. In the second stage, the $\mathrm{pH}$ was not controlled. With the accumulation of undissociated acids, the $\mathrm{pH}$ declined to induce the solventogenesis and prevent acidogenic fermentation [31].

The duration of $\mathrm{pH}$ control was investigated by varying the runtime for $0,12,24,36$ and $48 \mathrm{~h}$ (Figure 3C). Uncontrolled $\mathrm{pH}$ in an earlier period, for example $12 \mathrm{~h}$, was not favorable for AECC decomposition and butanol production, by reason that there were not sufficient cellulosomes synthesized and secreted by C. cellulovorans to degrade AECC, which was supported by the total cellulase activity during the first $48 \mathrm{~h}$ in Figures $1 \mathrm{~A}$ and $2 \mathrm{~A}$. ABE fermentation was severely restricted by the limited supply of carbon sources. Although a prolonged $\mathrm{pH}$ control stage for $48 \mathrm{~h}$ contributed to a high amount of substrate consumed $(46.8 \mathrm{~g} / \mathrm{L})$, organic acids were main products. There was only a minor decline in $\mathrm{pH}$ from 7.0 (only 0.79 ) attained, which caused rather low butanol production and solvents yield $(2.58 \mathrm{~g} / \mathrm{L}$ and $0.076 \mathrm{~g} / \mathrm{g}$, respectively) [31]. Although butanol production was not significantly different between cultures with the $\mathrm{pH}$ not controlled after $24 \mathrm{~h}$ and $36 \mathrm{~h}$, the former showed a lower $\mathrm{pH}$ minimum (5.54) during fermentation, which was more conducive to the production of solvents. In the following studies, the $\mathrm{pH}$ was controlled at 7.0 during the first $24 \mathrm{~h}$.

Few studies have paid attention to the effects of $\mathrm{pH}$ control on substrate utilization and butanol production during co-culture, and the $\mathrm{pH}$ is usually not regulated or optionally performed at compromise values for two strains, which always leads to slow lignocellulose decomposition or acidogenic fermentation [17,33]. The two-stage $\mathrm{pH}$ control strategy here provided a viable solution to promote substrate degradation and prevent acidogenic fermentation. Alternatively, the strategy could be carried out by adding cheap calcium carbonate or others with buffering capacity of the medium to reduce costs of $\mathrm{pH}$ control [34].

\section{$A B E$ fermentation from $A E C C$ under optimized co-culture conditions}

The performance of fed-batch ABE fermentation from AECC under the optimized co-culture conditions are described in Figure 4. Compared with the time courses shown in Figure 2, a double inoculum, 1\% (v/v) of C. beijerinckii had no obvious effects on AECC decomposition and total sugars accumulation during the first $24 \mathrm{~h}$; nevertheless, solventogenesis was triggered $12 \mathrm{~h}$ earlier, owing to a shortened duration of $\mathrm{pH}$ control, which together made for a shorter fermentation time of $80 \mathrm{~h}$. Earlier recovery of $C$. beijerinckii due to large inocula as well as a shorter runtime of $\mathrm{pH}$ control slowed the accumulation of total sugars and thus promoted the utilization of AECC. The feeding of AECC provided more adhesion sites for C. cellulovorans to colonize and extra enzymatic domain for cellulosomes [35], which thus increased the total cellulase activity and the supply of carbon sources for $C$. beijerinckii. With the slowing down of AECC degradation after $60 \mathrm{~h}$, the accumulated sugars began to be consumed. Although $C$. beijerinckii can utilize hexoses and pentoses simultaneously [21], the uptake of xylose and arabinose was rather poor and inefficient (Figure 4C) [29], which limited significantly the supply of ATP for organic acids transformation to solvents [27], hence there were some pentose, butyrate and acetate residual in final broth.

The co-culture produced $11.8 \mathrm{~g} / \mathrm{L}$ of ABE (acetone 2.64, butanol 8.30 and ethanol $0.87 \mathrm{~g} / \mathrm{L}$ ) and degraded $68.6 \mathrm{~g} / \mathrm{L}$ of AECC, which was $108 \%$ and $46.5 \%$ higher than that obtained under the initial unoptimized co-culture conditions. Comparing with attempts to engineer a native cellulolytic or solventogenic microbe, with the goal of developing the combined ability in an industrial microorganism to produce butanol (isobutanol) from lignocellulose in one pot reaction, the strategy of co-culture provided distinct advantages in terms of output and productivity (Table 1). Yet co-culture with different bacteria pairs and substrates also exhibited varied results. ABE production in the present work was $19.2 \%$ higher than that by a sequential co-culture of C. thermocellum and C. saccharoperbutylacetonicum strain N1-4, and the solvents productivity increased by 3.0-fold [19].

However, compared with the established ABE fermentation process from starch or sugars with other clostridia, the co-culture here still has a long road ahead in the ABE output, productivity and yield [2], which may be improved by promotion for the symbiosis in AECC saccharification, pentose uptake and utilization, organic acids reassimilation.

\section{Dynamics of the abundance of $C$. beijerinckii and C. cellulovorans during the co-culture process}

In the symbiotic system, $C$. beijerinckii and $C$. cellulovorans developed mutualistic relationships overall, at the same time commensal or competitive relationships as well in partial stages. It was necessary to figure out the roles of each strain at different periods. The population and relative abundance dynamics of both strains were quantified by real-time PCR (Figure 4D).

During the first $24 \mathrm{~h}$ after simultaneous inoculation, C. cellulovorans became more dominant in the mixed 

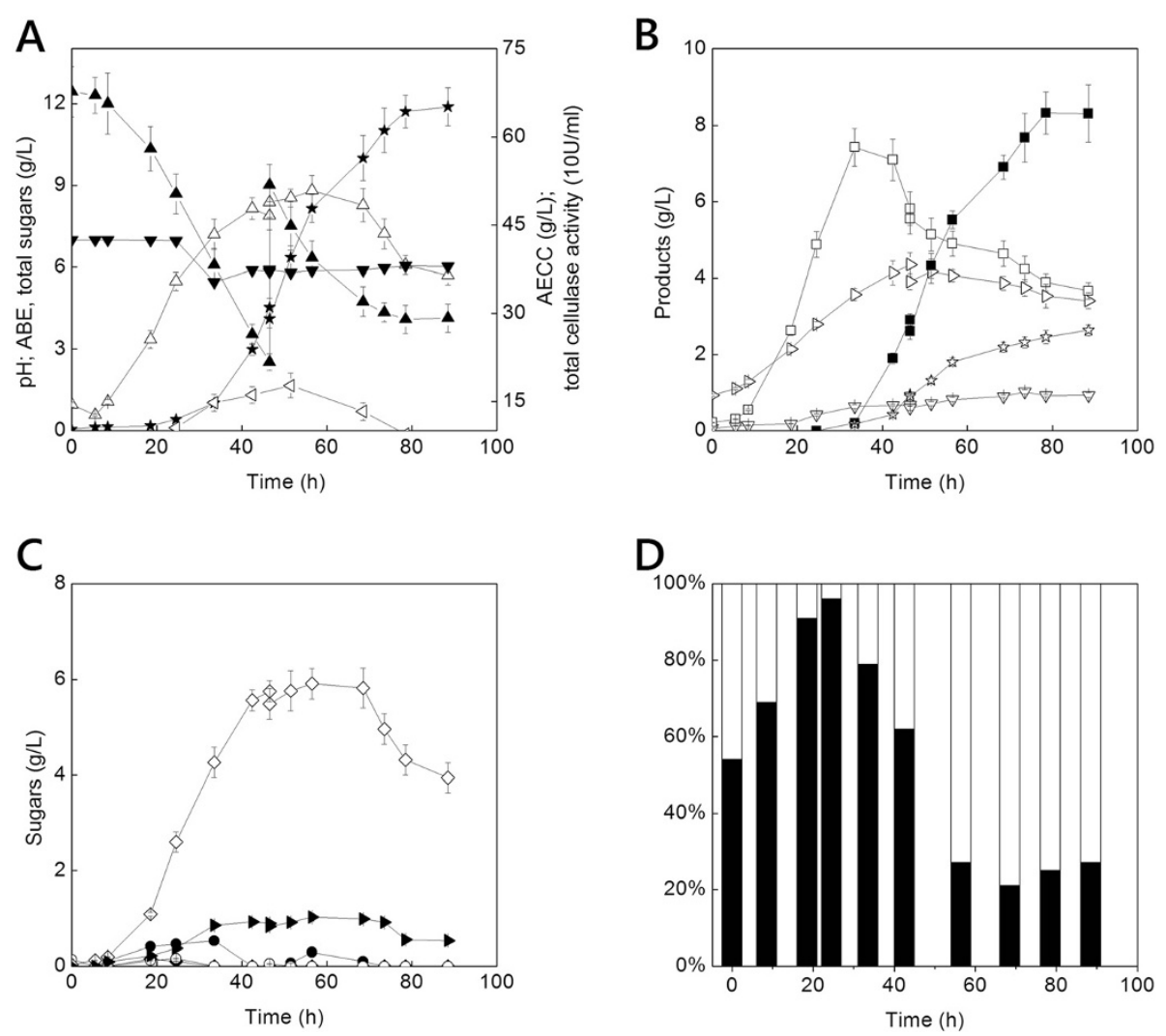

Figure 4 Time courses of co-culture using optimized strategies. The symbiosis degraded $68.6 \mathrm{~g} / \mathrm{L}$ AECC and produced $11.8 \mathrm{~g} / \mathrm{L}$ solvents, which was $108 \%$ and $46.5 \%$ higher than that obtained under the initial co-culture conditions. Besides, a real-time PCR assay based on the 165 rRNA gene sequence revealed the dynamics of the abundance for each strain. (A) Time courses of pH, solvents production total, cellulase activity, total sugars accumulation and utilization, AECC degradation. (B) Time courses of ABE and organic acids production, (C) Time courses of monosaccharides and dissaccharides accumulation and utilization, (D) Dynamics of relative abundace for C. beijerinckii and C. cellulovorans. $\mathbf{\Delta} A E C C, \triangle$ total sugars, $\mathbf{\nabla} \mathrm{pH}$,

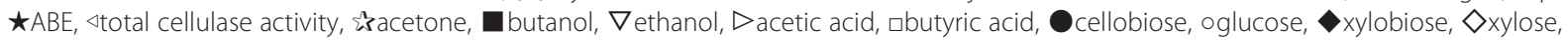
- arabinose, White, relative abundance of $C$. beijerinckii, Black, relative abundance of $C$. cellulovorans.

population. In other words, C. beijerinckii grew far slower than C. cellulovorans, which could be partly due to the lack of sufficient carbon sources (xylose and arabinose accumulated mainly) available. Moreover, interspecific competition from C. cellulovorans also limited the growth of C. beijerinckii, which explained why higher C. beijerinckii/C. cellulovorans inoculation ratios did not significantly affect ABE production (Figure 3B). C. beijerinckii need a period to adapt to the growth environment stresses, and simultaneous inoculation led to a better adaptation and growth. In the stage of $\mathrm{pH}$ control at 7.0, the environment benefited $C$. cellulovorans and there was more competition than cooperation.

From 24 to $56 \mathrm{~h}$, with the reduction of $\mathrm{pH}$ value, the growth of C. cellulovorans was negatively affected and slowed down [20], while C. beijerinckii seized the opportunity to proliferate rapidly and even exceeded $C$. cellulovorans. The low $\mathrm{pH}$ limited the growth and metabolism of C. cellulovorans and thus eased the competition from C. cellulovorans [20], which dramatically facilitated
C. beijerinckii. Furthermore, AECC degradation was greatly promoted by higher cellulase (cellulosome) activity at a low $\mathrm{pH}$ and the mitigation of feedback inhibition owing to the consumption of soluble sugars (Figures $2 \mathrm{~A}$ and $4 \mathrm{~A}$ ). At $36 \mathrm{~h}$, the low $\mathrm{pH}$ induced a switch in the metabolism of C. beijerinckii from acidogenesis to solventogenesis [38], in which the organic acids produced by $C$. cellulovorans were re-assimilated and transformed into solvents. The two-stage $\mathrm{pH}$ control strategy and butyrate accumulation by C. cellulovorans recovered C. beijerinckii and succeeded in shifting from competition to cooperation.

In the late fermentation period, AECC decomposition almost ceased and both strains were forced to compete for finite carbon source and nutrition. C. beijerinckii maintained dominance over C. cellulovorans, but the proportion declined as a result of accumulating butanol and rising $\mathrm{pH}$ with the re-assimilation of organic acids.

Competition and cooperation between C. cellulovorans and $C$. beijerinckii was preliminarily revealed by the dynamics of the abundance of both strains during the co-culture 
Table 1 Comparation of butanol (isobutanol or $\mathrm{ABE}$ ) production with varied lignocellulose by CBP

\begin{tabular}{|c|c|c|c|c|c|c|c|}
\hline Strain & Strategy & Substrate & $\begin{array}{l}\text { Isobutanol } \\
\text { (g/L) }\end{array}$ & $\begin{array}{l}\text { Butanol } \\
\text { (g/L) }\end{array}$ & $\begin{array}{l}\mathrm{ABE} \\
(\mathrm{g} / \mathrm{L})\end{array}$ & $\begin{array}{l}\text { ABE productivity } \\
(\mathrm{g} / \mathrm{L} / \mathrm{h})\end{array}$ & Reference \\
\hline C. cellulolyticum & $\begin{array}{l}\text { Expressing enzymes that direct the } \\
\text { conversion of pyruvate to isobutanol }\end{array}$ & Crystalline cellulose & 0.660 & & ND & ND & [16] \\
\hline Echerichia coli & $\begin{array}{l}\text { Expressing enzymes that invove } \\
\text { biomass digestion capabilities and } \\
\text { butanol synthesis pathways }\end{array}$ & $\begin{array}{l}\text { lonic liquid-treated } \\
\text { switchgrass }\end{array}$ & & 0.028 & ND & ND & [15] \\
\hline $\begin{array}{l}\text { Trichoderma reesei } \\
\text { and E. coli }\end{array}$ & $\begin{array}{l}\text { Co-culture of } T \text {. reesei and an } E \text {. coli } \\
\text { strain metabolically engineered to } \\
\text { produce isobutanol }\end{array}$ & $\begin{array}{l}\text { Pretreated corn } \\
\text { stover }\end{array}$ & 1.88 & & ND & ND & {$[36]$} \\
\hline $\begin{array}{l}\text { C. thermocellum and } \\
\text { C.acetobutylicum }\end{array}$ & $\begin{array}{l}\text { Sequential co-culture and feeding } \\
\text { butyrate }\end{array}$ & Cellulose solka floc & & 2.40 & 3.90 & 0.0232 & [18] \\
\hline $\begin{array}{l}\text { C. thermocellum and } \\
\text { C.acetobutylicum }\end{array}$ & Sequential co-culture & Crystalline cellulose & & 0.60 & 1.4 & 0.0053 & [19] \\
\hline $\begin{array}{l}\text { C. thermocellum and C. saccha- } \\
\text { roperbutylacetonicum strain } \\
\text { N1-4 }\end{array}$ & Sequential co-culture & Crystalline cellulose & & 7.9 & 9.9 & 0.0375 & [19] \\
\hline $\begin{array}{l}\text { C. thermocellum and } \\
\text { C. beijerinckii }\end{array}$ & Sequential co-culture & Crystalline cellulose & & 2.1 & 3.0 & 0.0114 & [19] \\
\hline $\begin{array}{l}\text { C. cellulolyticum and } \\
\text { C.acetobutylicum }\end{array}$ & Co-culture & Cellulose solka floc & & 0.80 & 1.1 & 0.0051 & [17] \\
\hline $\begin{array}{l}\text { Bacillus cellulolyticus and } \\
\text { C. acetobutylicum }\end{array}$ & Co-culture & $\begin{array}{l}\text { Pretreated palm } \\
\text { pressed fiber }\end{array}$ & & 0.49 & & ND & [33] \\
\hline $\begin{array}{l}\text { C. thermocellum and } \\
\text { C. beijerinckii }\end{array}$ & Sequential co-culture & AECC & & 8.75 & 16.0 & 0.0889 & {$[37]$} \\
\hline $\begin{array}{l}\text { C. cellulovorans and } \\
\text { C. beijerinckii }\end{array}$ & Co-culture & AECC & & 8.30 & 11.8 & 0.148 & this work \\
\hline
\end{tabular}

ND not determined.

process. The abundance of each strain was mainly regulated by the culture conditions, for example the $\mathrm{pH}$ value and nutrient availability. However, the molecular mechanism of competition and cooperation in the symbiotic system remained unclear.

It is known that quorum sensing (QS) plays an important role in determining the local bacterial concentration and proportion $[39,40]$, but the genes in both strains involved in QS have not been verified with certainty (Gene ID: 5295733 and 9610822 in Genebank). Further research for the production and recognition of signaling molecules within species and interspecies may contribute to understand how the symbiosis worked.

\section{Conclusion}

In this report, we developed a stable mutualistic system of C. cellulovorans and C. beijerinckii for ABE fermentation from AECC in one pot reaction. Optimization strategies were confirmed by investigating the effects of the co-culture conditions on butanol production and AECC degradation. Under the optimized conditions, the coculture produced $11.8 \mathrm{~g} / \mathrm{L}$ of $\mathrm{ABE}$ and degraded $68.6 \mathrm{~g} / \mathrm{L}$ of AECC in $80 \mathrm{~h}$, which were $108 \%$ and $46.5 \%$ higher than those obtained under the initial co-culture conditions. The dynamics of the abundance of $C$. beijerinckii and
C. cellulovorans revealed mechanisms of cooperation and competition between the two strains during the co-culture process.

These preliminary results illustrate the great potential of artificial symbiosis in biofuel production from lignocellulosic biomass by CBP. However, the mechanism of interspecific competition and cooperation in the community based on molecular is still unclear. The dynamics during co-culture remains to be studied further.

\section{Methods}

\section{Alkali extracted deshelled corn cobs (AECC)}

Deshelled corn cobs were cut into pieces approximately $1 \mathrm{~cm}$ in length, and were then ground to pass through 30-40 mesh (450-600 $\mu \mathrm{m})$. Alkali extracted fractions were prepared by autoclaving $6 \%(\mathrm{w} / \mathrm{v})$ corn cobs at $121^{\circ} \mathrm{C}$ for 20 min with $1 \%(\mathrm{w} / \mathrm{v}) \mathrm{NaOH}$, followed by neutralization with $1 \%(\mathrm{w} / \mathrm{v}) \mathrm{H}_{2} \mathrm{SO}_{4}$. These fractions were thoroughly washed with distilled water and dried at $80^{\circ} \mathrm{C}$ for $24 \mathrm{~h}$ [24].

The component of AECC was determined using a raw fiber extractor, FIWE 3 (Velp Scientifica/Goodwill (HK) Technology Ltd., Hong Kong, China) [41]. The cellulose, hemicellulose and lignin contents of AECC were 69.8, 27.4 and $1.47 \%(\mathrm{w} / \mathrm{w})$, respectively, compared to $44.9,33.2$ and $14.5 \%$ before alkali extraction. 


\section{Strain and medium}

Clostridium cellulovorans 743B was purchased from Deutsche Sammlung von Mikroorganismen und Zellkulturen GmbH (DSMZ, Braunschweig, Germany). The stock culture was maintained in $25 \%$ glycerol and frozen at $-80^{\circ} \mathrm{C}$.

Clostridium beijerinckii NCIMB 8052 was kindly provided by Professor Sheng Yang, Institute of Plant Physiology and Ecology, Shanghai Institutes for Biological Sciences (CAS). The stock culture was maintained in $25 \%$ glycerol and frozen at $-80^{\circ} \mathrm{C}$. C. beijerinckii was anaerobically precultured in TGY medium (1 L TGY medium contained $5 \mathrm{~g}$ of tryptone, $3 \mathrm{~g}$ of yeast extract, $2 \mathrm{~g}$ of glucose, $0.25 \mathrm{~g}$ of L-cysteine $\mathrm{HCl}$ and $0.001 \mathrm{~g}$ of resazurin, $\mathrm{pH}$ 6.5). It was incubated under static conditions at $37^{\circ} \mathrm{C}$ for $12-16 \mathrm{~h}$, at which point the log phase was reached.

C. cellulovorans were anaerobically pre-cultured in $200 \mathrm{~mL}$ of medium with AECC as the sole carbon source under static conditions at $37^{\circ} \mathrm{C}$ for $24 \mathrm{~h}$ before inoculation. The medium was slightly modified compared to that described before [20]. One liter of medium ( $\mathrm{pH} 7.0)$ contained $70.0 \mathrm{~g}$ of AECC, $1.5 \mathrm{~g}$ of $\mathrm{NH}_{4} \mathrm{Cl}, 1 \mathrm{~g}$ of $\mathrm{K}_{2} \mathrm{HPO}_{4} \cdot 3 \mathrm{H}_{2} \mathrm{O}$, $0.5 \mathrm{~g}$ of $\mathrm{KCl}, 0.5 \mathrm{~g}$ of $\mathrm{MgSO}_{4} \cdot 7 \mathrm{H}_{2} \mathrm{O}, 1.65 \mathrm{~g}$ of $\mathrm{CH}_{3} \mathrm{COONa}$, $0.5 \mathrm{~g}$ of yeast extract, $0.5 \mathrm{~g}$ of tryptone, $0.5 \mathrm{~g}$ of L-cysteine $\mathrm{HCl}, 0.001 \mathrm{~g}$ of resazurin, $20 \mathrm{~mL}$ of a trace metal solution [42], $100 \mu \mathrm{g}$ of $p$-aminobenzoic acid, $100 \mu \mathrm{g}$ of thiamine and $1 \mu \mathrm{g}$ of biotin. $\mathrm{NH}_{4} \mathrm{Cl}, \mathrm{CH}_{3} \mathrm{COONa}$, p-aminobenzoic acid, thiamine and biotin were filter-sterilized using a $0.22 \mu \mathrm{m}$ pore size filter, and the other materials were autoclaved at $121^{\circ} \mathrm{C}$ for $20 \mathrm{~min}$ followed by cooling to room temperature under $100 \% \mathrm{~N}_{2}$. The medium was also used for single and co-culture of $C$. beijerinckii and C. cellulovorans.

\section{$A B E$ fermentation from $A E C C$}

Single and co-culture of $C$. beijerinckii and C. cellulovorans were carried out in a $5 \mathrm{~L}$ bioreactor (Biotech-5BGH, Baoxing Bio-engineering Equipment Co. Ltd., Shanghai, China) with $2 \mathrm{~L}$ working volume with $\mathrm{pH}$ control if necessary by the automatic addition of $5 \mathrm{~N} \mathrm{NaOH}$. Agitation was kept constant at $100 \mathrm{rpm}$ and the temperature was maintained at $37^{\circ} \mathrm{C}$. Samples were taken at regular intervals for the analysis of biomass, substrate and products concentration.

The optimization of co-culture conditions was carried out in $500 \mathrm{~mL}$ shaken flasks with a $400 \mathrm{~mL}$ working volume by a reequipped six-channel refrigerated $\mathrm{pH}$ control feed shaker (SHpH6 shaker incubator, Shanghai Guoqiang Bioengineering Equipment Co. Ltd., Shanghai, China). Samples were taken at the end of fermentation for analysis and comparison.

The inoculum size of $C$. cellulovorans in all co-cultures was $10 \%(\mathrm{v} / \mathrm{v})$ if not otherwise indicated.

\section{Real-time PCR}

Total RNA was isolated from freshly collected culture samples using Trizol (Invitrogen, California, USA) following the manufacturer's instructions for bacteria. cDNA was synthesized from isolated RNA separately from reverse transcription PCRs using a PrimeScript ${ }^{\mathrm{TM}} \mathrm{RT}$ reagent Kit (for SYBR Green Assay, Takara, Shiga, Japan), following reaction conditions: $37^{\circ} \mathrm{C}$ for $15 \mathrm{~min}$ followed by $85^{\circ} \mathrm{C}$ for $5 \mathrm{~s}$. The resultant RNA and cDNA were aliquot and stored at $-80^{\circ} \mathrm{C}$.

An Eppendorf Mastercycler Realplex 4S system (Eppendorf, Hamburg, Germany) was used to quantify the copy number of $16 \mathrm{~S}$ rRNA genes from each strain. For the $16 \mathrm{~S}$ rRNA of C. cellulovorans (16S clocel), amplification using the forward primer 5'- ACGGCTTTGAGGTGACA GGA -3' and reverse primer 5'- ACCGAACTAACAATA AGGGTTGC-3' resulted in a $105 \mathrm{bp}$ fragment. For the $16 \mathrm{~S}$ rRNA of $C$. beijerinckii (16S cbei), amplification with the forward primer 5'- ACCCTTCGGGGCAGGAA-3' and reverse primer 5'- GCGAGTGCTCAACTAAATGGTA GC-3' gave a 125 bp fragment. A SYBR Premix Ex Taq kit (Takara, Shiga, Japan) was used under the following reaction conditions: $90^{\circ} \mathrm{C}$ for $10 \mathrm{~s}$ followed by 40 cycles of $90^{\circ} \mathrm{C}$ for $15 \mathrm{~s}$ and $60^{\circ} \mathrm{C}$ for $15 \mathrm{~s}$. All assays were performed at least in triplicate. Those products with copy numbers between $10^{4}$ and $10^{13}$ were used as gradient templates to generate standard curves [32].

Since $16 S$ clocel (amplification fragment) and $16 \mathrm{~S} \mathrm{cbei}$ (amplification fragment) are expressed with 9 and 14 copies in the genomes of C. cellulovorans and C. beijerinckii, respectively, the abundance of each strain in the co-culture system was determined by Equations (1) and (2).

$$
\begin{aligned}
& \text { Abundance of C. cellulovorans } \\
& \qquad=\frac{16 \text { Sclocelcopynumber } / 9}{16 \text { Sclocelcopynumber } / 9+16 \text { Scbeicopynumber } / 14}
\end{aligned}
$$

$$
\begin{aligned}
& \text { Abundance of } C \text {. beijerinckii } \\
& \qquad=\frac{16 \text { Scbeicopynumber } / 14}{16 \text { Sclocelcopynumber } / 9+16 \text { Scbeicopynumber } / 14}
\end{aligned}
$$

\section{Analysis}

Cell growth on glucose or cellobiose was determined by the measurement of optical density at $600 \mathrm{~nm}\left(\mathrm{OD}_{600}\right)$ by a spectrophotometer (UV mini-1240, Shimadzu Corporation, Tokyo, Japan). Cell density of $C$. beijerinckii (OD $\left.{ }_{600} 1.2-1.5\right)$ was previously normalized to 1.0 of $\mathrm{OD}_{600}$ before inoculating with various volumes.

On particles of AECC, the cell mass was estimated based on bacterial cell protein measurement. The cell dry weightprotein correlation was established for bacteria grown on cellobiose, and this correlation was assumed to be the same for cells grown on AECC. That is: cell mass = pellet protein $/ f_{\mathrm{P} / \mathrm{CDW}}$, where $\mathrm{f}_{\mathrm{P} / \mathrm{CDW}}=$ (pellet protein $) /($ cell dry 
weight). A value of 0.57 was calculated [43]. The pellet protein measurement was described previously [44]. The AECC concentration was calculated by subtracting the estimated cell mass from the pellet dry weight.

Total cellulase activity was measured as indicated before [44] with a minor modification. $10 \mathrm{ml}$ sample was centrifuged $\left(8,000 \mathrm{~g}\right.$ for $15 \mathrm{~min}$ at $\left.4^{\circ} \mathrm{C}\right)$ and washed twice with $0.9 \%(\mathrm{w} / \mathrm{v})$. The pellet was resuspended in $10 \mathrm{ml} 25 \mathrm{mM}$ phosphate buffer ( $\mathrm{pH}$ 7.0). The incubation was performed at $37^{\circ} \mathrm{C}$ for $30 \mathrm{~min}$ using $\mathrm{AECC}$ as the substrate. Liberation of reducing sugars was measured by dinitrosalicyclic acid method with glucose as the standard. One unit of total cellulase activity was defined as the amount of enzyme which released $1 \mu \mathrm{mol}$ of total sugars per min. [45] Total cellulase activity was represented by the pellet cellulase activity, because the supernatant cellulase activity was rather low (lower than $0.05 \mathrm{U}$ throughout in the work) compared with the pellet cellulase activity [44].

$\mathrm{ABE}$ and organic acids were measured by gas chromatography (GC; 6820; HP-INNOWAX (19091 N-113) capillary chromatographic column; temperature programming [46]; Agilent Technologies, California, USA).

The concentration of total sugars was estimated using the phenol-sulfuric acid method as previously described [47]. Glucose, cellobiose, xylose, xylobiose, arabinose and other sugars were measured using a Dionex Ultimate ${ }^{\mathrm{ma}} 3000$ HPLC (Thermo fisher scientific, Massachusetts, USA) equipped with a corona-charged aerosol detector (CAD). The HPLC column (HPX-87C; Aminex Resin-based) was purchased from BioRad (California, USA). Column temperature was $76^{\circ} \mathrm{C}$, and the mobile phase (pure water) flow rate was maintained at $0.4 \mathrm{~mL} / \mathrm{min}$.

Reactor productivity was estimated as the total $\mathrm{ABE}$ produced in $\mathrm{g} / \mathrm{L}$ divided by the fermentation time and was expressed as $\mathrm{g} / \mathrm{L} / \mathrm{h}$. ABE yield was calculated as $\mathrm{g}$ of ABE produced per $g$ of AECC used.

The reported results are the average values of three experiments carried out on different occasions. The experimental variation between parallel samples from different reactors under the same conditions was less than $10 \%$.

\section{Abbreviations}

ABE: Acetone-butanol-ethanol; AECC: Alkali extracted deshelled corn cobs; CBP: Consolidated bioprocessing

\section{Competing interests}

The authors declare that they have no competing interests.

\section{Authors' contributions}

ZW, MW and $J$ carried out the studies and drafted the manuscript, and $Y L$, LY, PC participated in the project design and manuscript preparation. All authors read and approved the final manuscript.

\section{Acknowledgments}

This work was financially supported by the Natural Science Foundation of China (Grant No. 20876141) and the Program for Zhejiang Leading Team of S\&T Innovation (2011R50002).

\section{Author details}

${ }^{1}$ Key Laboratory of Biomass Chemical Engineering of Ministry of Education, Department of Chemical and Biological Engineering, Zhejiang University, Hangzhou 310027, China. ${ }^{2}$ Current address: Third Institute of Ocaeangraphy, State Oceanic Administration, Xiamen 361005, China.

Received: 18 February 2014 Accepted: 17 June 2014

Published: 15 July 2014

\section{References}

1. Dürre P: Biobutanol, an attractive biofuel. Biotechnol J 2007, 2:1525-1534.

2. Gu Y, Jiang Y, Wu H, Liu X, Li Z, Li J, Xiao H, Shen Z, Dong H, Yang Y, Li Y, Jiang $W$, Yang S: Economical challenges to microbial producers of butanol: feedstock, butanol ratio and titer. Biotechnol J 2011, 6:1348-1357.

3. Ezeji T, Blaschek H: Fermentation of dried distillers' grains and solubles (DDGS) hydrolysates to solvents and value-added products by solventogenic clostridia. Bioresour Technol 2008, 99:5232-5242.

4. Qureshi N, Saha B, Cotta M: Butanol production from wheat straw hydrolysate using Clostridium beijerinckii. Bioprocess Biosyst Eng 2007, 30:419-427.

5. Qureshi N, Ezeji T, Ebener J, Dien B, Cotta M, Blaschek H: Butanol production by Clostridium beijerinckii. Part I: Use of acid and enzyme hydrolyzed corn fiber. Bioresour Technol 2008, 99:5915-5922.

6. Qureshi N, Saha B, Dien B, Hector R, Cotta M: Production of butanol (a biofuel) from agricultural residues: part I - Use of barley straw hydrolysate. Biomass Bioenerg 2010, 34:559-565.

7. Qureshi N, Saha B, Hector R, Dien B, Hughes S, Liu S, Iten L, Bowman M, Sarath G, Cotta M: Production of butanol (a biofuel) from agricultural residues: part II - Use of corn stover and switchgrass hydrolysates. Biomass Bioenerg 2010, 34:566-571.

8. Lu C, Zhao J, Yang S, Wei D: Fed-batch fermentation for n-butanol production from cassava bagasse hydrolysate in a fibrous bed bioreactor with continuous gas stripping. Bioresour Technol 2012, 104:380-387.

9. Bayer E, Lamed R, Himmel M: The potential of cellulases and cellulosomes for cellulosic waste management. Curr Opin Biotechnol 2007, 18:237-245.

10. Lynd L, van Zyl W, McBride J, Laser M: Consolidated bioprocessing of cellulosic biomass: an update. Curr Opin Biotechnol 2005, 16:577-583.

11. Lopez-Contreras A, Smidt H, van der Oost J, Claassen P, Mooibroek H, de Vos W: Clostridium beijerinckii cells expressing Neocallimastix patriciarum glycoside hydrolases show enhanced lichenan utilization and solvent production. Appl Environ Microbiol 2001, 67:5127-5133.

12. Perret S, Casalot L, Fierobe H, Tardif C, Sabathe F, Belaich J, Belaich A: Production of heterologous and chimeric scaffoldins by Clostridium acetobutylicum ATCC 824. J Bacteriol 2004, 186:253-257.

13. Mingardon F, Perret S, Belaich A, Tardif C, Belaich J, Fierobe H: Heterologous production, assembly, and secretion of a minicellulosome by Clostridium acetobutylicum ATCC 824. Appl Environ Microbiol 2005, 71:1215-1222.

14. Mingardon $F$, Chanal A, Tardif C, Fierobe $H$ : The issue of secretion in heterologous expression of Clostridium cellulolyticum cellulase-encoding genes in Clostridium acetobutylicum ATCC 824. Appl Environ Microbiol 2011, 77:2831-2838

15. Bokinsky G, Peralta-Yahya P, George A, Holmes B, Steen E, Dietrich J, Lee T, Tullman-Ercek D, Voigt C, Simmons B, Keasling J: Synthesis of three advanced biofuels from ionic liquid-pretreated switchgrass using engineered Escherichia coli. Proc Natl Acad Sci 2011, 108:19949-19954.

16. Higashide W, Li Y, Yang Y, Liao J: Metabolic engineering of Clostridium cellulolyticum for production of isobutanol from cellulose. Appl Environ Microbiol 2011, 77:2727-2733.

17. Petitdemange $E$, Fond $O$, Caillet $F$, Petitdemange $H$, Gay R: A novel one step process for cellulose fermentation using mesophilic cellulolytic and glycolytic clostridia. Biotechnol Lett 1983, 5:119-124.

18. Yu E, Chan M, Saddler J: Butanol production from cellulosic substrates by sequential co-culture of Clostridium thermocellum and C. acetobutylicum. Biotechnol Lett 1985, 7:509-514.

19. Nakayama S, Kiyoshi K, Kadokura T, Nakazato A: Butanol production from crystalline cellulose by cocultured Clostridium thermocellum and Clostridium saccharoperbutylacetonicum N1-4. Appl Environ Microbiol 2011, 77:6470-6475.

20. Sleat $R$, Mah R, Robinson R: Isolation and characterization of an anaerobic, cellulolytic bacterium, Clostridium cellulovorans sp. nov. Appl Environ Microbiol 1984, 48:88-93. 
21. Ezeji T, Qureshi N, Blaschek H: Butanol production from agricultural residues: impact of degradation products on Clostridium beijerinckii growth and butanol fermentation. Biotechnol Bioeng 2007, 97:1460-1469.

22. Liu Z, Ying Y, Li F, Ma C, Xu P: Butanol production by Clostridium beijerinckii ATCC 55025 from wheat bran. J Ind Microbiol Biotechnol 2010, 37:495-501.

23. Doi R, Tamaru Y: The Clostridium cellulovorans cellulosome: an enzyme complex with plant cell wall degrading activity. Chem Rec 2001, 1:24-32

24. Rani K, Swamy M, Seenayya G: Production of ethanol from various pure and natural cellulosic biomass by Clostridium thermocellum strains SS21 and SS22. Process Biochem 1998, 33:435-440.

25. Giallo J, Gaudin C, Belaich J, Petitdemange E, Cailletmangin F: Metabolism of glucose and cellobiose by cellulolytic mesophilic Clostridium sp. strain H10. Appl Environ Microbiol 1983, 45:843-849.

26. Lee $S$, Cho M, Park C, Chung Y, Kim J, Sang B, Um Y: Continuous butanol production using suspended and immobilized Clostridium beijerinckii NCIMB 8052 with supplementary butyrate. Energ Fuel 2008, 22:3459-3464.

27. Loyarkat S, Cheirsilp B, Umsakul K: Direct conversion of sugars and organic acids to biobutanol by non-growing cells of clostridium spp. incubated in a nitrogen-free medium. Appl Biochem Biotechnol 2013, 171:1726-1738.

28. Kim J, Block D, Mills D: Simultaneous consumption of pentose and hexose sugars: an optimal microbial phenotype for efficient fermentation of lignocellulosic biomass. App/ Microbiol Biotechnol 2010, 88:1077-1085.

29. Xiao H, Li Z, Jiang Y, Yang Y, Jiang W, Gu Y, Yang S: Metabolic engineering of D-xylose pathway in Clostridium beijerinckii to optimize solvent production from xylose mother liquid. Metab Eng 2012, 14:569-578.

30. Andric P, Meyer A, Jensen P, Dam-Johansen K: Effect and modeling of glucose inhibition and in situ glucose removal during enzymatic hydrolysis of pretreated wheat straw. Appl Biochem Biotechnol 2010, 160:280-297.

31. Maddox I, Steiner E, Hirsch S, Wessner S, Gutierrez N, Gapes J, Schuster K The cause of "acid crash" and "acidogenic fermentations" during the batch acetone-butanol-ethanol (ABE-) fermentation process. J Mol Microbiol Biotechnol 2000, 2:95-100.

32. Geng A, He Y, Qian C, Yan X, Zhou Z: Effect of key factors on hydrogen production from cellulose in a co-culture of Clostridium thermocellum and Clostridium thermopalmarium. Bioresour Technol 2010, 101:4029-4033.

33. Ponthein W, Cheirsilp B, Yupapin P, PivsaArt S, Ohgaki H: Development of Acetone Butanol Ethanol (ABE) Production from palm pressed fiber by Mixed Culture of Clostridium sp and Bacillus sp. In Proceeding of 9th Eco-Energy and Materials Science and Engineering Symposium: 25-27 May 2011; Chiang Rai, Thailand. Edited by Yupapin P, Pivsa-Art S, Ohgaki H: Elsevier; 2011:459-467.

34. Ren C, Gu Y, Hu S, Wu Y, Wang P, Yang Y, Yang C, Yang S, Jiang W: Identification and inactivation of pleiotropic regulator $\mathrm{CcpA}$ to eliminate glucose repression of xylose utilization in Clostridium acetobutylicum. Metab Eng 2010, 12:446-454.

35. Gelhaye E, Gehin A, Petitdemange H: Colonization of crystalline cellulose by Clostridium cellulolyticum ATCC 35319. Appl Environ Microbiol 1993, 59:3154-3156

36. Minty J, Singer M, Scholz S, Bae C, Ahn J, Foster C, Liao J, Lin X: Design and characterization of synthetic fungal-bacterial consortia for direct production of isobutanol from cellulosic biomass. Proc Natl Acad SCi 2013, 110:14592-14597.

37. Lin Y, Wen Z, Zhu L, Lin J, Cen P: Butanol production from corncob in the sequential co-culture of Clostridium thermocellum and Clostridium beijerinckii. J Chem Eng Chinese U 2013, 3:444-449.

38. Millat $T$, Janssen $H$, Thorn $G$, King J, Bahl H, Fischer R, Wolkenhauer O: A shift in the dominant phenotype governs the $\mathrm{pH}$-induced metabolic switch of Clostridium acetobutylicumin phosphate-limited continuous cultures. Appl Microbiol Biotechnol 2013, 97:6451-6466.

39. Choudhary S, Schmidt-Dannert C: Applications of quorum sensing in biotechnology. Appl Microbiol Biotechnol 2010, 86:1267-1279.

40. Zuroff T, Curtis W: Developing symbiotic consortia for lignocellulosic biofuel production. Appl Microbiol Biotechnol 2012, 93:1423-1435.

41. Van Soest J, Robertson B: Systems of Analysis for Evaluating Fibrous Feeds. In Proceeding of workshop on Standardization of Analytical Methodology for Feeds:12-14 March 1979; Ottawa, Canada. Edited by Pigdea W, Balch C, Graham M. Ottawa, ON, CA: IDRC; 1979:49-60.

42. Ferguson $\mathrm{T}$, Mah $\mathrm{R}$ : Isolation and characterization of an $\mathrm{H}_{2}$-oxidizing thermophilic methanogen. Appl Environ Microbiol 1983, 45:265-274.

43. Zhang $Y$, Lynd $L$ : Quantification of cell and cellulase mass concentrations during anaerobic cellulose fermentation: development of an enzyme-linked immunosorbent assay-based method with application to Clostridium thermocellum batch cultures. Anal Chem 2003, 75:219-227.

44. Desvaux M, Guedon E, Petitdemange H: Cellulose catabolism by Clostridium cellulolyticum growing in batch culture on defined medium. Appl Environ Microbiol 2000, 66:2461-2470.

45. Miller G: Use of dinitrosalicylic acid reagent for determination of reducing sugar. Anal Chem 1959, 31:426-428.

46. Liu G, Zhu W, Hu T: Analysis of acetone-butanol fermentation products by capillary gas chromatography. Food Fermn Ind 2007, 33:115-117.

47. Saha S, Brewer C: Determination of the concentrations of oligosaccharides, complex type carbohydrates, and glycoproteins using the phenol-sulfuric acid method. Carbohydr Res 1994, 254:157-167.

\section{doi:10.1186/s12934-014-0092-5}

Cite this article as: Wen et al: Artificial symbiosis for acetone-butanolethanol (ABE) fermentation from alkali extracted deshelled corn cobs by co-culture of Clostridium beijerinckii and Clostridium cellulovorans. Microbial Cell Factories 2014 13:92.

\section{Submit your next manuscript to BioMed Central and take full advantage of:}

- Convenient online submission

- Thorough peer review

- No space constraints or color figure charges

- Immediate publication on acceptance

- Inclusion in PubMed, CAS, Scopus and Google Scholar

- Research which is freely available for redistribution 